\title{
Phenotype Prevalence of Blood Group Systems (ABO, Rh, Kell) in Voluntary, Healthy Donors-Experience of a Tertiary Care Hospital in Delhi, North India
}

Neeraj Garg ${ }^{1 *}$, Deepak Kumar Singh ${ }^{1}$, Reena Tomar ${ }^{1}$ and Bharat Singh ${ }^{2}$

${ }^{1}$ Department of Pathology, UCMS \& GTB Hospital, Delhi, India

${ }^{2}$ Regional Blood Transfusion Centre, UCMS \& GTB Hospital, Delhi, India

"Corresponding author: Neeraj Garg, Consultant Pathologist, Fortis Memorial Research Institute, Sector 44, Opposite HUDA City Centre Metro Station, Gurgaon 122002, Haryana, India, Tel: 8802454756; E-mail: xs2neerajgarg@gmail.com

Received date: Jul 03, 2015, Accepted date: Aug 13, 2015, Publication date: Aug 18, 2015

Copyright: ( 2015 Garg N, et al. This is an open-access article distributed under the terms of the Creative Commons Attribution License, which permits unrestricted use, distribution, and reproduction in any medium, provided the original author and source are credited.

\begin{abstract}
Objective: To study phenotypic prevalence of $\mathrm{ABO}, \mathrm{Rh}$ and Kell blood group system

Material and Method: Voluntary blood donors were tested for red cell antigen of ABO, Rh (D, C, c, E, e) and Kell (K) blood group systems. Each sample was tested using LISS/Coombs ABO-Rh gel card and DiaClon Rh subgroups $+\mathrm{K}$ gel card. Calculations of antigen and phenotypes frequencies were expressed as percentages and allele frequencies were expressed under the standard assumption of Hardy-Weinberg equilibrium.
\end{abstract}

Results: Study included a total of 2769 voluntary blood donors in which blood group distribution was (A-22.3\%, $\mathrm{B}-39.2 \%, \mathrm{AB}-8.9 \%, \mathrm{O}-29.6 \%$ ). Rh antigen was found positive in $93.8 \%$ and negative in $6.2 \%$ donors. Amongst $\mathrm{Rh}$ positive antigens, e was the most common $(98.7 \%)$ followed by $\mathrm{C}(91.8 \%), \mathrm{c}(55.2 \%)$ and $\mathrm{E}(21.1 \%)$. DCe/DCe $(44.7 \%)$ was the most common phenotype. Distributions of Rh minor antigens were also assessed in different blood group and were found similar. For the Kell System, only $1.6 \%$ was $\mathrm{K}$ positive which is less than previous study from India.

Conclusion: The prevalence of red cell antigen and phenotype frequencies differs in different populations. The knowledge of the prevalence of blood group antigens will be helpful in rational use of blood and blood products. It will also prevent alloantibodies formation in multiple transfused patients against minor antigens. Gel-card test is a rapid, simple and practical method for population studies.

Keywords: Blood group antigens; Blood donors; Prevalence; Phenotype; Coombs test

\section{Introduction}

The blood transfusion services aim to ensure adequate and safe blood to minimize the development of transfusion transmitted infections and transfusion reactions. William Harvey first described the circulation of blood in man in 1628 and the first published report on human-to-human blood transfusion by James Blundell in 1818 $[1,2]$. A total of $308 \mathrm{RBC}$ antigens are now recognized by the International Society of Blood Transfusion (ISBT), 270 of which are clustered in 30 blood group systems [3]. The discovery of the ABO blood group system was made by Karl Landsteiner in 1900 [4]. The genes are located at chromosome $9 \mathrm{q} 34.2$. There are three allelic genes that are inherited in Mendelian fashion. The frequencies of $\mathrm{ABO}$ phenotypes are variable among different ethnic populations. In $\mathrm{Rh}$ blood group three different systems of nomenclature have been developed to describe the genes and antigens- The Wiener system, the Fisher-Race system, and the Rosenfield numeric terminology. Wiener proposed that the $\mathrm{Rh}$ antigens were the products of a single gene. The Fisher-Race nomenclature was based on the theory that reactions observed with various $\mathrm{Rh}$ antisera could be explained by three pairs of allelic genes: Cc, Dd, and Ee. Rosenfield proposed a system of nomenclature that was based on serologic findings. The Rh antigens are encoded by two genes: RHD and RHCE. The genes are located at chromosome 1p36.11. RHD encodes for the D antigen, whereas RHCE encodes for the $\mathrm{Cc}$ and Ee antigens. The $\mathrm{d}$ antigen does not exist. There are 49 antigens out of which the most important are D, C, E, c, and e. Less than $3 \%$ of individuals exposed to the C, c, E, and $\mathrm{e}$ antigens become alloimmunized therefore pretransfusion testing is not routinely performed for these antigens. The Kell blood group system was discovered in 1946 and was named after Mrs. Kellner and consists of 27 antigens. Kell locus is located at $7 \mathrm{q} 34$. The $\mathrm{k}$ antigen is a highfrequency antigen that is present in more than $98 \%$ of whites and blacks. The $\mathrm{K}$ antigen is much less common but very immunogenic. Because of this, anti-K is often encountered [5]. Coomb introduced the indirect antiglobulin test by which there was a rapid increase in the identification of alloantibodies [6].

The transfusion of ABO compatible but unknown phenotype blood may result in alloimmunization especially in patients who required multiple-transfusion in hematologic disorders and malignancies. The most important red blood cell alloantibodies are directed towards the RH (anti -D, -C, -E, -c and -e) and KELL (anti-K). In present study phenotypic prevalence of $\mathrm{ABO}, \mathrm{Rh}$ and kell antigens was studied in regular voluntary blood donors to get an insight of their distribution and would ensure supply of antigen negative compatible blood without delay to prevent development of transfusion reaction in alloimmunized patients [7]. 
Citation: Garg N, Singh DK, Tomar R, Singh B (2015) Phenotype Prevalence of Blood Group Systems (ABO, Rh, Kell) in Voluntary, Healthy Donors-Experience of a Tertiary Care Hospital in Delhi, North India. J Blood Disord Transfus 6: 297. doi:10.4172/2155-9864.1000297

Page 2 of 4

\section{Materials and Methods}

A total of 2769 voluntary blood donors were tested for red cell antigen typing of $\mathrm{ABO}, \mathrm{Rh}(\mathrm{D}, \mathrm{C}, \mathrm{c}, \mathrm{E}, \mathrm{e})$ and Kell (K) blood group systems. Each sample was tested using LISS/Coombs ABO-Rh gel card and DiaClon Rh subgroups $+\mathrm{K}$ gel card. (Diamed AG, Cressier sur Morat, Switzerland).

Red cells from each donor sample was prepared as $5.0 \%$ suspension in low ionic strength saline (LISS) and Rh antigen (C, E, c, e) typing was performed by gel card (Diamed AG, Cressier sur Morat, Switzerland). Ten micro litre of donor cell suspension was added to micro tubes followed by centrifuge at $910 \mathrm{rpm}$ for 10 minutes. Agglutinated cells forming a red line on the surface of gel or dispersed in gel are considered positive. A compact button of cells on bottom of the micro tube indicated the absence of the corresponding antigen.

Calculations of antigen and phenotypic frequencies of various blood group systems were calculated by dividing the total number of donors positive for a particular antigen phenotype with total number of donors screened and were expressed as percentages. Allele frequencies were calculated under the standard assumption of Hardy-Weinberg equilibrium.

The study was conducted after taking approval from Ethics Committee.

\section{Results}

Study included a total of 2769 voluntary blood donors (Table 1) of which blood group distribution was (A-22.3\%, B-39.2\%, AB-8.9\%, O-29.6\%) (Figure 1). Rh antigen was found positive in $93.8 \%$ and negative in $6.2 \%$ (Figure 2). Amongst $\mathrm{Rh}$ antigens, e was the most common (98.7\%) followed by C (91.8\%), c (55.2\%) and E (21.1\%). DCe/DCe (44.7\%) was the most common phenotype (Figure 3). Distribution of Rh antigen was also assessed in different blood group and was found similar (Table 2). For the Kell System, only $1.6 \%$ was $\mathrm{K}$ positive (Table 2 and Figure 3). Gel Cards showing antigen profile from selected donors (Figure 4).

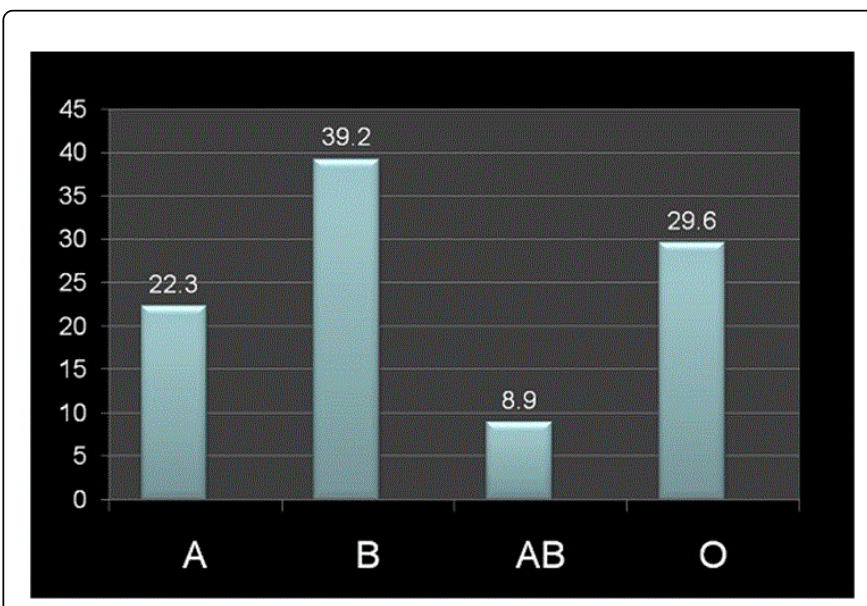

Figure 1: $\mathrm{ABO}$ Blood group antigen prevalence in voluntary donors.

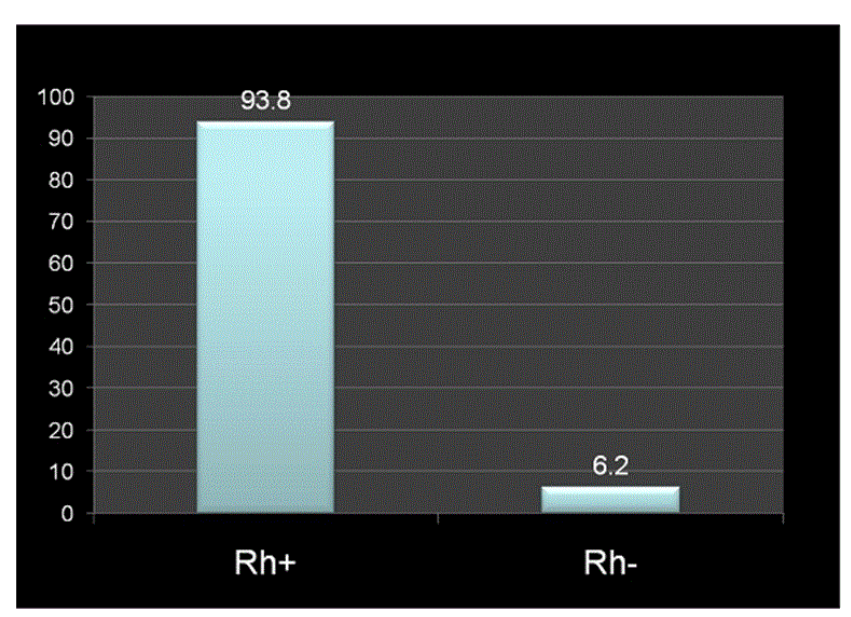

Figure 2: $\mathrm{Rh}$ blood group antigen $\mathrm{D}$ prevalence in voluntary donors.

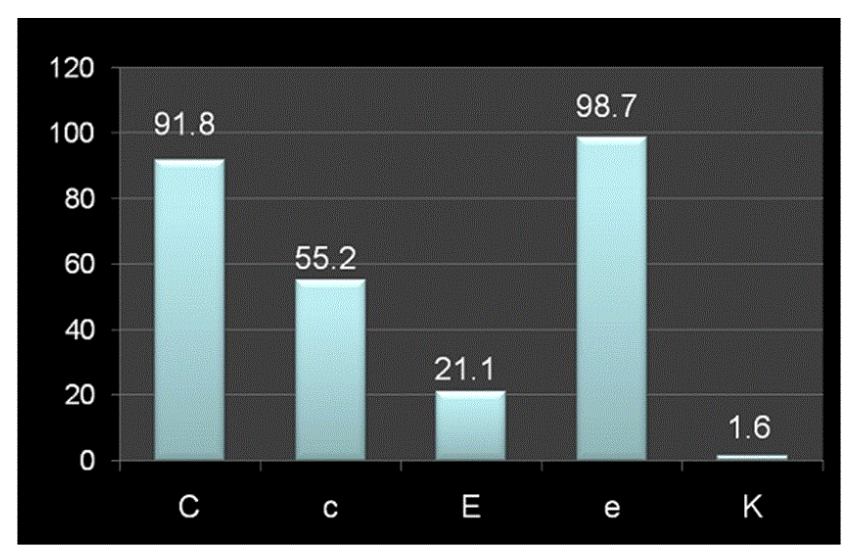

Figure 3: Minor Rh blood group and kell antigen prevalence (\%).

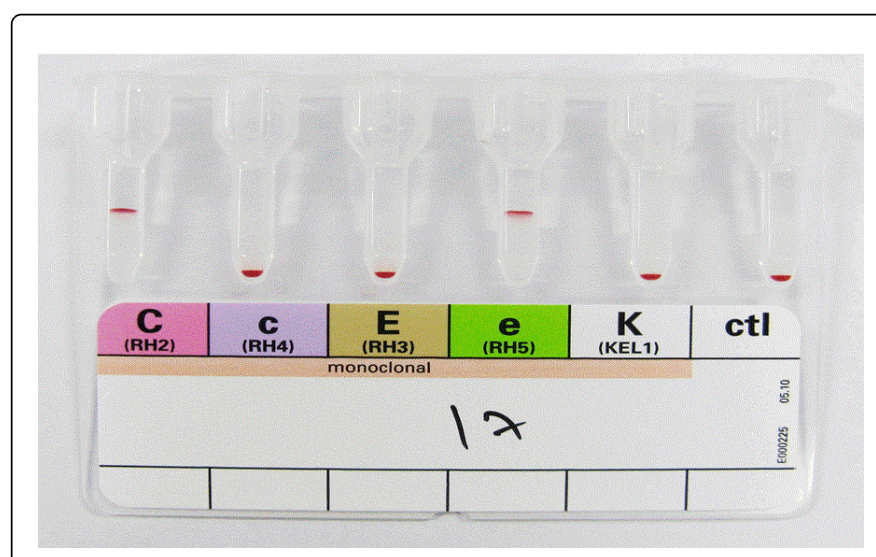

Figure 4: Gel Cards showing antigen profile from selected donors. 
Citation: Garg N, Singh DK, Tomar R, Singh B (2015) Phenotype Prevalence of Blood Group Systems (ABO, Rh, Kell) in Voluntary, Healthy Donors-Experience of a Tertiary Care Hospital in Delhi, North India. J Blood Disord Transfus 6: 297. doi:10.4172/2155-9864.1000297

Page 3 of 4

\begin{tabular}{|l|l|l|l|l|}
\hline & Minimum & Maximum & Mean & Std. Deviation \\
\hline Age & 18 & 55 & 30.32 & 7.4 \\
\hline Weight & 45 & 98 & 69.78 & 9.7 \\
\hline Gender (M:F) & $01: 00.0$ & & \\
\hline
\end{tabular}

Table 1: Demographic profile of voluntary donors.

\begin{tabular}{|l|l|l|l|l|}
\hline & A & B & AB & O \\
\hline C & 91.2 & 91.6 & 93.5 & 92.3 \\
\hline C & 57.6 & 54.3 & 56.3 & 54.3 \\
\hline E & 20.1 & 21.3 & 20.8 & 21.8 \\
\hline e & 98.9 & 98.4 & 99.6 & 98.7 \\
\hline K & 1.3 & 1.5 & 2 & 2 \\
\hline
\end{tabular}

Table 2: Minor Rh blood group antigen and Kell antigen prevalence in $\mathrm{ABO}$ blood groups (in\%).

As in Table 3, genotyping was not done, nine presumed phenotypes were found to be present in our population, the most common being $\mathrm{DCe} / \mathrm{DCe}(\mathrm{R} 1 \mathrm{R} 1 ; 44.7 \%)$ and ce/ce $\left(\mathrm{rr}^{\prime \prime}\right)$ was the most rare phenotype observed. Weak D phenotype was not observed on red cells donors.

\begin{tabular}{|c|c|c|c|c|c|}
\hline Phenotypes* & Present Study & Sarkar et al. [11] & Thakral et al. [12] & Whites & Blacks \\
\hline DCe/DCe (R1R1) & $44.60 \%$ & $35.20 \%$ & $43.80 \%$ & 17.6 & 2.9 \\
\hline DCe/dce (R1r) & $32.60 \%$ & $30.70 \%$ & $30 \%$ & 31.1 & 8.8 \\
\hline DCe/DcE (R1R2) & $14 \%$ & $8.10 \%$ & $8.22 \%$ & 11.8 & 3.7 \\
\hline DcE/DcE (R2R2) & $0.80 \%$ & $0.70 \%$ & $1.45 \%$ & 2 & 1.3 \\
\hline Dce/dce (R0r) & $1.30 \%$ & $2.20 \%$ & $0.97 \%$ & 3 & 22.9 \\
\hline DcE/dce (R2r) & $5.90 \%$ & $5.90 \%$ & $8.95 \%$ & 10.4 & 5.7 \\
\hline dce/dce (rr) & $0.07 \%$ & $0.30 \%$ & $5.81 \%$ & 15 & 7 \\
\hline dCe/dce (r'r) & - & $2.50 \%$ & $0.56 \%$ & 1 & 1 \\
\hline dce/dcE (rr") & - & & $0.24 \%$ & 1 & Rare \\
\hline
\end{tabular}

Table 3: Comparison of Rh phenotypic frequencies in north Indian blood donors, Whites and Blacks.

\section{Discussion}

The distribution of different blood group system in the present study were ABO (A-22.3\%, B-39.2\%, AB-8.9\%, O-29.6\%), Rh (positive-93.8\%, negative-6.2\%) and Kell (1.6\% K). B blood group was found to be most common similar to other studies from India [8]. In $\mathrm{Rh}$ system $\mathrm{D}$ antigen frequency was found to be $93.8 \%$ which was comparable to other studies from India [9-11]. On the basis of expression of different antigen of Rh system most common phenotype was found to be of DCe/DCe (R1R1) //DCe/Ce (Rr) (44.7\%) and similar findings by Agarwal (42.93\%), Thakral et al. (43.8\%) and Sarkar (35.2\%) [8,9,11]. However, the above phenotype frequency is present in only $17.6 \%$ of white and $2.9 \%$ of black population. Ce/ce phenotype frequency was least common $(0.07 \%)$ as reported by Sarkar
Since genotyping was not done, the comparison of Rh phenotype frequencies in our population with previous study from India, Whites and Blacks population was done (Table 3).

(0.3\%). Thakral et al. showed ce/cE as the rarest phenotype [9]. Most common phenotypes in white DCe/dce (31.1\%) and in blacks Dce/dce (22.9\%) population was reported.

The $\mathrm{K}$ antigen frequency was $1.6 \%$, similar to that was reported in Blacks (2\%) and Agarwal et al. (1.97\%) but lower than study by Thakral et al. (5.68\%) and that in Whites (8.8\%). Rh phenotypes differ in different part of world populations. Phenotypes observed in blood donors would also be prevalent in patients. Knowledge of the distribution of $\mathrm{Rh}(\mathrm{D})$ antigen in blood donor population also helps in pre transfusion testing. Frequency of $\mathrm{Rh}(\mathrm{D})$ negative person among different part of world population varies from $40 \%$ to less than $1.0 \%$. Incidence of anti-D is very uncommon in country with low frequency of $\mathrm{Rh}$ (D) antigen. In Indian population due to relatively high prevalence of $\mathrm{D}$ negative, $\mathrm{D}$ typing is a must [11]. Among $\mathrm{Rh}$ minor 
Citation: Garg N, Singh DK, Tomar R, Singh B (2015) Phenotype Prevalence of Blood Group Systems (ABO, Rh, Kell) in Voluntary, Healthy Donors-Experience of a Tertiary Care Hospital in Delhi, North India. J Blood Disord Transfus 6: 297. doi:10.4172/2155-9864.1000297

Page 4 of 4

antigens those are present less commonly in predominant phenotype alloantibody would be more common against them. Anti-c being the most common $(38.8 \%)$ followed by anti-E (22.2\%) were most commonly reported in transfused patients [12]. In our department we have been providing antigen negative compatible blood to Thalassemia patients routinely to prevent alloimmunization against $\mathrm{Rh}$ (anti-D, -C, -E, -c and -e) and KEL (anti-K) antigens.

Blood group phenotypes are easily identified by the presence or absence of the RBC surface antigens. In present study phenotypic prevalence of $\mathrm{ABO}, \mathrm{Rh}$ and kell antigens was studied in regular voluntary blood donors so that it will lead to a donor data bank on $\mathrm{RBC}$ antigens that will provide antigen negative compatible blood to patients with multiple alloantibodies especially in multiple transfused patients and also prevent alloantibody formation against minor antigens. Same phenotypes can be produced by several different genotypes. The exact genotype of any individual can only be identified by DNA analysis. Phenotype frequency of Rh group is speculated on the basis of distributions of antigens.

\section{Conclusion}

Multiple transfused patients develop alloantibody against some of the rare antigens (CcEe and kell). Therefore it is important to match the rare antigens before issuing blood. Antigen typing of the various blood group systems will help in preparation of indigenous screening cell and identification panels. Keeping in regard of regional differences in antigen frequency of various blood group systems, due to ethnic heterogenicity, larger studies needs to be carried out in various parts of World. Because of its simplicity and efficacy, the gel-card test is a rapid and practical method for population studies.

\section{Disclosure}

The author(s) declare(s) that there is no conflict of interest regarding the publication of this paper.

\section{References}

1. Harvey W (1928) Exercitatio Anatomica de Motu Cordis et Sanquinis in Animalibus. An Anatomical Exercise on the Motion of the Heart and Blood in Animals.

2. Blundell J (1818) Experiments on the Transfusion of Blood by the Syringe. Med Chir Trans 9: 56-92.

3. Daniels G, Castilho L, Flegel WA, Fletcher A, Garratty G, et al. (2009) International Society of Blood Transfusion Committee on terminology for red blood cell surface antigens: Macao report. Vox Sang 96: 153-156.

4. Landsteiner K (1901) Ueber Agglutinationserscheinungen normalen menschlichen Blutes. Wien. Klin. Wochenschr 14: 1132-1134.

5. Kathryn E, Webert James W, Smith Donald M (2009) Red Cell, Platelet, and White Cell Antigens Wintrobeâs Clinical Hematology. (12th edtn.). Lippincott Williams \& Wilkins, 22: 631-638.

6. Cate JC 4th, Reilly N (1999) Evaluation and implementation of the gel test for indirect antiglobulin testing in a community hospital laboratory. Arch Pathol Lab Med 123: 693-697.

7. Brecher ME (2005) Technical manual. (15thedn). American Association of Blood Banks, Bethesda.

8. Agarwal N, Thapliyal RM, Chatterjee K (2013) Blood group phenotype frequencies in blood donors from a tertiary care hospital in north India. Blood Res 48: 51-54.

9. Thakral B, Saluja K, Sharma RR, Marwaha N (2101) Phenotype frequencies of blood group systems (Rh, Kell, Kidd, Duffy, MNS, P, Lewis, and Lutheran) in north Indian blood donors. Transfusion and Apheresis Science 43: 17-22.

10. Stella T. Chou, Connie M (2005) Westhoff Technical manual (15th edtn.). American Association of Blood Banks, Bethesda. The Rh System: 392.

11. Sarkar RS, Philip J, Mallhi RS, Yadav P (2013) Proportion of Rh phenotypes in voluntary blood donors. Med J Armed Forces India 69: 330-334.

12. Thakral B, Saluja K, Sharma RR, Marwaha N (2008) Red cell alloimmunization in a transfused patient population: a study from a tertiary care hospital in north India. Hematology 13: 313-318.
This article was originally published in a special issue, entitled: "Rh Blood Group System", Edited by Smita Mahapatra, SCB Medical College \& Hospital, India 